\title{
Treatment of behavioral and psychological symptoms of dementias with psychopharmaceuticals: a review
}

This article was published in the following Dove Press journal:

Neuropsychiatric Disease and Treatment

\author{
Jiří Masopust ${ }^{1-4}$ \\ Dita Protopopová ${ }^{4}$ \\ Martin Vališ ${ }^{2,3}$ \\ Zbyšek Pavelek ${ }^{2,3}$ \\ Blanka Klímová ${ }^{5}$ \\ 'Department of Psychiatry, Charles \\ University in Prague, Prague, Czech \\ Republic; ${ }^{2}$ Faculty of Medicine in \\ Hradec Kralove and University \\ Hospital, Hradec Kralove, Czech \\ Republic; ' ${ }^{3}$ Department of Neurology, \\ Charles University in Prague, \\ Prague, Czech Republic; ${ }^{4}$ National \\ Institute of Mental Health, Klecany, \\ Czech Republic; ${ }^{5}$ Department of \\ Applied Linguistics, University of \\ Hradec Kralove, Hradec Kralove, \\ Czech Republic
}

\begin{abstract}
Behavioral and psychological symptoms represent common complications in patients with different types of dementia. Predominantly, they comprise psychosis, agitation and mood disorders, disinhibited behavior, impairment of the sleep and wakefulness rhythm, wandering, perseveration, pathological collecting, or shouting. Their appearance is related to more rapid progression of the disease, earlier institutionalization, use of physical restraints, and higher risk of mortality. Consequently, appearance of behavioral and psychological symptoms of dementia leads to higher costs of care provided and greater distress for caregivers. Clinical guidelines recommend nonpharmacological approaches as the first choice in the treatment of behavioral and psychological symptoms. Pharmacological therapy should be initiated only if the symptoms were not the result of somatic causes, did not respond to nonpharmacological interventions, or were not caused by the prior medication. Acetylcholinesterase inhibitors, memantine, antipsychotic drugs, antidepressants, mood stabilizers, and benzodiazepines are used. This review summarizes the current findings about the efficacy and safety of the treatment of the neuropsychiatric symptoms in dementias with psychopharmaceuticals. Recommendations for treatment with antipsychotics for this indication are described in detail as this drug group is prescribed most often and, at the same time, is related to the highest risk of adverse effects and increased mortality.
\end{abstract}

Keywords: dementia, behavioral and psychological symptoms, treatment, psychopharmaceuticals, adverse effects

\section{Introduction}

Behavioral and psychological symptoms of dementia (BPSD) represent common complications in patients with different types of dementia. Predominantly, they comprise psychosis, agitation and mood disorders, disinhibited behavior, impairment of the sleep and wakefulness rhythm, wandering, perseveration, pathological collecting, or shouting. ${ }^{1}$ Usually, neuropsychiatric symptoms are not isolated. They tend to appear in certain clusters. ${ }^{2,3}$ These clusters could be classified according to the most prevalent symptoms as predominantly affective, psychotic, hyperactive, or apathic. ${ }^{4}$ The occurrence of BPSD has been documented in most types of dementias - Alzheimer's disease (AD), vascular dementia (VaD), dementia in Parkinson's disease, frontotemporal dementia (FTD), and in mild cognitive impairment. ${ }^{5}$

To assess the presence and severity of the symptoms, it is recommended to use assessment scales like Neuropsychiatric Inventory (NPI) or Behavioral Pathology in Alzheimer's Disease Rating Scale. ${ }^{4}$

Most patients with dementia develop at least one of the BPSD in the course of their disease. Their appearance causes increased distress for the patient and those 
around - mostly the caregivers. ${ }^{6}$ Presence of BPSD is related to more rapid progression of the disease (especially in depressive and psychotic symptoms), earlier institutionalization, use of physical restraints, and higher risk of mortality. As a result, the costs of care provided increase. ${ }^{4,7-9}$

It is difficult to choose safe and effective pharmacological treatment because of the paucity of data from randomized controlled trials (RCTs). Most often, antipsychotic drugs are prescribed, although there is no solid evidence of their efficacy in individual neuropsychiatric symptoms. Concurrently, the administration of antipsychotic drugs entails the risk of occurrence of adverse effects. ${ }^{10,11}$ A study by van der Spek et $\mathrm{a}^{12}$ showed alarming results. Based on an index comprising indication, dosage, drug interactions, duplicate administration, and duration of treatment, the authors determined that the BPSD were correctly treated with psychopharmaceuticals in accordance with all criteria in only $10 \%$ of patients. ${ }^{12}$

This review summarizes the current findings on efficacy and safety of the treatment of the neuropsychiatric symptoms in dementias with psychopharmaceuticals. Recommendations about treatment with antipsychotics in this indication are described in detail as this drug group is prescribed most often and, at the same time, is related to the highest risk.

\section{Approach to the treatment of BPSD}

The causes for the development of the BPSD are usually multifactorial. Causal and contributing factors could be classified as biological, psychological, social, and environmental. Individual factors differ in their degree of modifiability. ${ }^{4}$ Before the initiation of any treatment for BPSD, it is necessary to examine the patient carefully and remove any possible precipitating factors. Infections (including dental infections), pain, and dehydration are the most common triggers of neuropsychiatric symptoms. BPSD could also be induced by visual or hearing deficit. ${ }^{13}$ It is necessary to reduce common and unreasonable polypharmacy. Administration of drugs with anticholinergic effects (eg, urological drugs) and benzodiazepines is not appropriate. Digitalis and diuretics are also risky regarding the occurrence of the BPSD. ${ }^{8}$

Clinical guidelines recommend nonpharmacological approaches as the first choice in the treatment of BPSD. Most evidence favors behavioral therapy, interventions focused on caregivers, communication skills training of the staff nursing the patients with dementia, and music therapy with a transient effect on agitation and anxiety. Other approaches include aromatherapy (lavender and lemon balm in particular), massages, and bright light therapy, all of which can contribute to alleviation of BPSD. ${ }^{6,8,14}$
Pharmacological therapy should be initiated only if the symptoms did not have somatic causes or did not respond to nonpharmacological interventions or were not caused by prior medication. Indicated and well-performed pharmacotherapy could prevent hazardous physical restraint of elderly patients. According to Kuronen et al, ${ }^{15}$ more than half of hospitalized patients with dementia had been physically restrained within the previous 24 hours. Psychotic symptoms and the use of benzodiazepines constituted the risk factors. Conversely, patients using antipsychotics and antidepressants were physically restrained less often. Acetylcholinesterase inhibitors (AChEI), memantine, antipsychotic drugs, antidepressants, mood stabilizers, and benzodiazepines comprise the medication for the treatment of BPSD. ${ }^{5}$

\section{Antidepressants}

Depression and anxiety are among the most common behavioral disorders in dementia. Antidepressants can influence cognition by direct action on specific neurotransmitters or secondarily, by improving the depressive symptoms. ${ }^{16}$ Administration of the antidepressant can improve not only the cognition and affective symptoms, but partially, also agitation and aggression. ${ }^{1,17}$ Given the profile of adverse effects, tricyclic antidepressants are totally inappropriate for the elderly population. Selective serotonin reuptake inhibitors (SSRIs), particularly sertraline, citalopram, and escitalopram, have mild efficacy and good tolerance. ${ }^{8}$ Analyses of the effect of the antidepressants on neuropsychiatric symptoms other than depression in patients with dementia were published. ${ }^{18,19}$ Two placebo-controlled studies showed that the treatment with sertraline and citalopram was related to significant reduction in agitation. A recent study showed the efficacy of an average dose of citalopram on moderate agitation in patients with a mild degree of cognitive impairment. Conversely, patients with severe agitation and a severe cognitive deficit were more likely to experience adverse effects. Citalopram also partially alleviated delusions, anxiety, irritability, and emotional lability. However, it worsened cognitive functions and caused slight prolongation of the QTc interval on ECG. ${ }^{20,21}$ In the study by Viscogliosi et al, ${ }^{22}$ citalopram was as efficient in treatment of agitation as olanzapine and quetiapine, and it was tolerated better. This study did not record any effect of citalopram on the QTc interval or cognitive functions. Generally, administration of citalopram and escitalopram in higher doses is not recommended in elderly patients with dementia given the risk of prolonging the QTc interval. Furthermore, during treatment with SSRI, it is necessary to monitor the risk of development of hyponatremia, nausea, 
vomiting, diarrhea, tremor, gastrointestinal bleeding, and sleep deterioration. There is less evidence for efficacy and tolerance of trazodone in the treatment of BPSD. More data are available for VaD and FTD. ${ }^{23}$ Only a small open study showed the positive effect of mirtazapine. ${ }^{24}$

\section{Anticonvulsants and mood stabilizers}

From controlled trials studying mood anticonvulsants/ stabilizers, there are data concerning carbamazepine and valproate only. Carbamazepine was effective in the treatment of noncognitive symptoms of dementia, especially agitation, aggression, and hostility. ${ }^{25}$ Its administration carries several adverse effects including hematotoxicity. It is also a strong inducer of cytochrome oxidase system P450. In the treatment of BPSD, valproate did not differ from the placebo, and its administration was burdened by frequent adverse effects. Moreover, it can adversely affect cognitive functions. ${ }^{26}$ The Cochrane Database System Review showed that low doses of valproate were ineffective, while the higher doses led to frequent adverse effects like sedation (odds ratio $[\mathrm{OR}]=2.64$ ), gastrointestinal problems $(\mathrm{OR}=4.12)$, urinary tract infections $(\mathrm{OR}=3.02)$, and falls $(\mathrm{OR}=2.08) .{ }^{27}$ Currently, there is only limited clinical experience and evidence for the use of lamotrigine and gabapentin. Based on the available data, anticonvulsants cannot be recommended for common use for this indication despite the possible benefits in some patients.

\section{Acetylcholinesterase inhibitors and memantine}

AChEI and memantine have only a mild effect on BPSD. According to a meta-analysis, the effect of AChEI on BPSD is statistically significant; however, the clinical outcome remains unclear. ${ }^{28}$ The effect could be visible after several weeks of administration. Mostly, they tend to influence symptoms of depression, anxiety, and tension. Memantine is more effective on agitation, delusions, hallucinations, and aggression. ${ }^{1,4}$ The influence of AChEI and memantine on different symptoms provides a good theoretical premise for their use in some combination. ${ }^{29-31}$ This was determined by a recent meta-analysis, which showed a significantly higher effect of memantine in combination with donepezil in the treatment of BPSD than the administration of donepezil in monotherapy. ${ }^{32}$ Administration of AChEI could be connected with diarrhea, nausea, vomiting, as well as bradycardia and syncope. Caution should be taken especially in patients with arrhythmias or patients using bradycardia-inducing medication. Data supporting the efficacy of gingko biloba extract
EGb 761 on BPSD (except psychosis) and the reduction of the distress on the caregivers are available. ${ }^{33}$

\section{Benzodiazepines}

Benzodiazepines are prescribed for up to $15 \%-30 \%$ of patients with dementia living in medical centers and homes for the elderly. ${ }^{19}$ According to a Finnish cohort study, patients with Alzheimer's dementia have 4.5 times higher risk of being prescribed benzodiazepines in comparison with their peers without dementia. ${ }^{34}$ Administration of these drugs is associated with deterioration of cognitive functions, sedation, paradoxical disinhibition, risk of falls, and fracture of the femoral neck. It is recommended not to administer benzodiazepines to the patients with dementia. ${ }^{35}$ For necessary cases, drugs with a shorter duration of action (midazolam, cinolazepam, and oxazepam) could be used singularly, but they should not be administered under hypnotic indication. "Z-hypnotics" (zopiclone, zolpidem, and zaleplon) can have similar adverse effects among elderly patients as benzodiazepines. In patients with dementia, we use them only for a limited time in low doses to treat insomnia. ${ }^{4}$

\section{Antipsychotics}

Antipsychotics are prescribed for up to $60 \%$ of patients with dementia treated in medical centers or homes for the elderly. ${ }^{36}$ Prescriptions of antipsychotics slightly decreased following warnings from the Food and Drug Administration (FDA) in $2005^{37}$ (significantly increased risk of mortality for secondgeneration antipsychotics [A2G] in comparison with the placebo) and 2008 (warning extended to first-generation antipsychotics [A1G]). Currently, A2G are prescribed more often than the $\mathrm{A} 1 \mathrm{G}$. Common use of $\mathrm{A} 2 \mathrm{G}$ is controversial for the following three reasons: in studies performed, the effect size (ES) was low, tolerance was rather poor, and there was a probable connection to increased mortality. ${ }^{1}$

\section{Efficacy of antipsychotics}

From the A1G group, the most available data concern haloperidol, which was effective in suppressing aggression (in dose of $1.2-3.5 \mathrm{mg} /$ day; ES 0.31 ; $95 \%$ CI 0.49 to -0.13$).{ }^{38}$ On the other hand, it had only a minor effect on agitation and psychotic symptoms. Thus, it is not certain if the benefits outweighed the adverse effects of this drug. ${ }^{1}$

The efficacy of A2G in the treatment of BPSD was observed by more than 20 randomized controlled studies. Given the lower occurrence of extrapyramidal symptoms (EPS), A2G are tolerated better and their efficacy is comparable with $\mathrm{A} 1 \mathrm{G}$. In a study, risperidone was more effective 
than haloperidol..$^{39}$ Data are available to support the efficacy of olanzapine, risperidone, quetiapine, aripiprazole, and amisulpride to a certain degree. Recent findings favor risperidone and olanzapine as a drug of choice for the management of psychosis and aggression in patients with dementia. ${ }^{1}$

Extensive study evaluated off-label use of $\mathrm{A} 2 \mathrm{G}$ in patients with BPSD in 14 placebo-controlled trials. Certain symptoms were followed, for example, psychosis, aggression, and mood changes. Overall, ES was poor, but statistically significant $(0.12-0.20)$ in aripiprazole, olanzapine, and risperidone. Quetiapine proved to be ineffective. ${ }^{40}$ When comparing the antipsychotic effect, only risperidone performed better than the placebo. Similarly, an extensive blinded, 36-week-long, multicenter CATIE-AD study, which compared the effects of olanzapine, risperidone, and quetiapine in 421 patients with Alzheimer's dementia, showed the higher efficacy of risperidone and olanzapine on BPSD in comparison with the placebo. This did not apply to quetiapine. ${ }^{41}$ Concurrently, it shows that the relatively poor efficacy of antipsychotics is accompanied by noticeable adverse effects.

A meta-analysis of 23 RCTs showed the efficacy of A2G in the treatment of BPSD in comparison with the placebo. ${ }^{42}$ Aripiprazole and risperidone performed better than the placebo in reducing the psychiatric symptoms. With regard to the effect on cognitive functions, aripiprazole, risperidone, olanzapine, and quetiapine were effective.

The results of placebo-controlled studies may underestimate the real efficacy of antipsychotics on BPSD because of the implemented methodology and selection of enrolled patients. Unpublished data from studies concerning clozapine, paliperidone, asenapine, and ziprasidone are available. In the treatment of BPSD, these antipsychotics are rarely used or not at all. ${ }^{9}$ Also, the benefits of administration of antipsychotics to treat BPSD longer than 12 weeks remain unclear although $60 \%$ of patients with dementia are administered this type of medication for longer than 6 months. ${ }^{43}$ Important findings were brought by a post-hoc analysis of the CATIE-AD trial. It determined that insufficient improvement after 2 weeks of the treatment with antipsychotic medication is a significant predictive factor of nonresponsiveness after 8 subsequent weeks. Therefore, it would be beneficial to change the treatment. ${ }^{44}$

Administration of D2/D3 receptor blocker amisulpride to treat psychosis in patients with dementia using a low-dose therapeutic window of $50 \mathrm{mg} /$ day has only had a theoretical foundation based on imaging studies. ${ }^{45}$

\section{Adverse effects of antipsychotics}

The use of A1G in patients with dementia is restricted by the occurrence of EPS - Parkinsonism, dystonia, and tardive dyskinesia. Prolongation of the QTc interval on ECG and arrhythmias is also more common. During A2G administration, motor adverse effects are less expressed; however, thromboembolic episodes, aspiration pneumonia, metabolic symptoms, falls, and deterioration of cognitive performance are more common. Both groups of antipsychotics carry a higher risk of stroke. ${ }^{46,47}$

According to the CATIE-AD study, the adverse effects of olanzapine, risperidone, and quetiapine outweighed their benefits. Parkinsonism occurred more often during treatment with olanzapine and risperidone (12\%) than with quetiapine $(2 \%)$ or placebo $(1 \%)$. During treatment with olanzapine and risperidone, states of confusion were registered more often (in $18 \%$ and $11 \%$ of patients, respectively). The occurrence of sedation (15\%-24\%) and weight gain did not differ among the compared antipsychotics. The incidence of falls, fractures, and other injuries was frequent during the treatment with antipsychotics (7\%-17\%); however, it was comparable with the placebo $(15 \%)$. From among the severe adverse effects, stroke and transitory ischemic attack were rarely described during the treatment with both antipsychotics $(1 \%-2 \%)$ and placebo $(1 \%){ }^{41} \mathrm{~A}$ review of 18 placebo-controlled studies concerning the use of $\mathrm{A} 2 \mathrm{G}$ in patients with dementia brought similar outcomes. ${ }^{48}$ The EPS occurred more often in risperidone and olanzapine. Conversely, in aripiprazole and quetiapine, they were comparable with the placebo. The weight gain was most often caused by olanzapine and risperidone. The excessive sedation was described in all studied antipsychotics. Given its minor potential to induce EPS, quetiapine is appropriate for the treatment of psychotic symptoms in Parkinson's disease or, as the case may be, Lewy body dementia.

The negative effect of the antipsychotic medication on cognitive functions has been discussed. The meta-analysis did not prove this effect of antipsychotics. ${ }^{49}$ Conversely, the severity of dementia and the duration of treatment worsened cognitive deterioration. Given the limited data, authors recommend interpreting these conclusions with caution. Nevertheless, they assume that falls and cerebrovascular accidents (CVAs) represent a higher risk of antipsychotic medication than its effect on cognitive functions. ${ }^{50}$

\section{Mortality during treatment with antipsychotics}

In 2005, the US FDA issued a warning concerning increased mortality of the patients with dementia and BPSD treated with A2G. ${ }^{38}$ An identical warning from the European Medicines Agency (EMA) followed. The information was included in the summary of product characteristics (SPC) of antipsychotics. The warning was based on the results 
from published and unpublished data and, particularly, on the conclusion of a meta-analysis of 17 randomized controlled studies. It determined that there was approximately twice the risk of mortality during therapy with olanzapine, risperidone, quetiapine, and aripiprazole in comparison with the placebo. ${ }^{37}$

Another meta-analysis brought similar outcomes. ${ }^{41}$ Observational studies brought data from larger groups of patients during the long-term administration of antipsychotics. A study concluded by Wang et $\mathrm{al}^{51}$ found the mortality risk increased by $30 \%$ during treatment with $\mathrm{A} 1 \mathrm{G}$ in comparison with $\mathrm{A} 2 \mathrm{G}$. Another study showed similar results (risk increase by $26 \%$ in $\mathrm{A} 1 \mathrm{G}$ versus $\mathrm{A} 2 \mathrm{G}) .{ }^{52}$ On the contrary, another 1-year-long cohort study showed that the mortality risk was lower by $17 \%$ during treatment with $\mathrm{A} 2 \mathrm{G}$ in comparison with A1G administration. ${ }^{53}$ None of these studies evaluated mortality for individual antipsychotics. In 2008, the warning was also extended to A $1 \mathrm{G} .{ }^{54}$

The risk of mortality grows with an increasing dose of the antipsychotic medication, and it is at its highest level shortly after initiation of the therapy..$^{9,50,51}$ Some newer studies focused on the risks of individual antipsychotics. A retrospective 6-month-long study showed the highest relative risk $(\mathrm{RR})$ of mortality during administration of haloperidol $(R R=1.54)$. Risperidone $(R R=1)$ and olanzapine $(\mathrm{R}=0.99)$ had comparable risks. The treatment with quetiapine was related to the lowest risk of mortality $(\mathrm{R}=0.73)$. Haloperidol carried the highest risk within the first 30 days of administration, and afterward, risk sharply declined. For other medications, the risk was most significant within the initial 120 days of administration and slowly decreased during the following 60 days. The relative safety of quetiapine was balanced by low efficacy on aggression, agitation, and psychosis. ${ }^{38}$ An observational study ${ }^{55}$ showed the highest mortality risk during treatment with higher doses of haloperidol and the lowest risk during administration of low doses of quetiapine. The survival of patients with dementia treated with antipsychotics compared with the placebo patients decreased significantly in association with the duration of treatment in the 36-month placebo-controlled DART-AD study (Dementia Antipsychotic Withdrawal Trial). Seventy percent of patients on antipsychotics survived 12 months in comparison with 76\% of patients in the placebo group. However, only $30 \%$ of patients on antipsychotics survived 36 months in comparison with $59 \%$ of patients in the placebo group. ${ }^{56}$

However, the study results may be distorted. Most studies are performed in a vulnerable group of seniors living in homes for the elderly, or in similar facilities. These individuals are primarily more ill and are at greater risk than their peers living at home. In mortality studies, patients without antipsychotic medication are enrolled as a control group for the users of antipsychotics. There could be a great difference between these groups in severity of dementia and occurrence of somatic risks, which is reflected in the observed mortality. ${ }^{9}$

The most common causes of death during the treatment of BPSD with antipsychotic drugs are cardiovascular, cerebrovascular, respiratory, and infectious (pneumonia) diseases.

In controlled studies, risk of CVA in patients with dementia using antipsychotics was 1.3-2 times higher in comparison with controls. ${ }^{57}$ Antipsychotics can contribute to the development of CVA through orthostatic hypotension, hyperprolactinemia causing endothelial dysfunction or thrombogenic effect. After an episode of hypotension, catecholamines are released and cause vasoconstriction. Antipsychotic-induced sedation may lead to venous stasis and dehydration related to hemoconcentration. The risk of CVA is comparable in A1G and A2G and peaks within the initial weeks of antipsychotics administration. Diabetes mellitus, hypertension, atrial fibrillation, $\mathrm{VaD}$, and occurrence of stroke in the medical history represent preexisting risk factors for developing $\mathrm{CVA} .{ }^{46} \mathrm{~A}$ recent meta-analysis of observational studies showed increased risk (OR 1.49; 95\% CI 1.24-1.77) in A 1 G. However, there is only a slightly increased risk during the administration of $\mathrm{A} 2 \mathrm{G}$ (OR 1.31; 95\% CI 0.74-2.30). Administration of any specific antipsychotic drug entailed low risk (OR 1.17; 95\% CI 1.08-1.26) of CVA. ${ }^{58}$

The treatment with both first and second generation of antipsychotics is related to increased risk of developing pneumonia. ${ }^{59}$ Possible causes comprise aspirations because of EPS, dysphagia, sedation, or dry mouth influenced by the effects of antipsychotics on dopamine, cholinergic, and histamine $\mathrm{H} 1$ receptors. ${ }^{9}$

Elderly patients with dementia should be monitored due to cardiovascular adverse effects. Prolonging the QTc interval on ECG may result in Torsade des pointes or other potentially fatal ventricular arrhythmia. Among the available antipsychotics, sertindole, haloperidol, quetiapine, and ziprasidone prolong the QTc interval. ${ }^{60}$ It is necessary to be aware of this complication when treating patients with cardiac diseases and using other drugs that prolong the QTc interval. Given the risk of orthostatic hypotension, olanzapine should not be administered to elderly patients who previously underwent syncope. ${ }^{61}$

The treatment with antipsychotics is related to the high risk of venous thromboembolism (VTE). ${ }^{62}$ This information is listed in the SPC. An extensive study of cases and 
controls $(n=72,591)$ in patients with dementia determined the increased risk of VTE (OR 1.23 [1.01-1.60]) during the administration of antipsychotics in comparison with not using the medication. ${ }^{63}$ There was no difference between the treatment with $\mathrm{A} 1 \mathrm{G}$ and $\mathrm{A} 2 \mathrm{G}$. The relation of VTE to individual medical products has not been studied in patients with dementia.

Comparatively speaking, little data are available on the incidence of metabolic symptoms in patients with BPSD treated with antipsychotics. The CATIE-AD study described weight gain during the use of olanzapine and quetiapine. ${ }^{64}$ Rondanelli et al ${ }^{65}$ did not observe any weight gain, appearance of type 2 diabetes mellitus, or abnormalities of lipid metabolism during treatment with low doses of $A 2 G$ in patients with dementia. According to current findings, it is not clear to what extent potential metabolic symptoms of antipsychotics administered to patients with dementia can contribute to their increased mortality.

Some data give evidence about the possible contribution of EPS, falls, and deterioration of cognitive functions during administration of antipsychotics in increased mortality of patients with dementia. ${ }^{46}$

\section{Recommendations for the treatment of BPSD with antipsychotics}

First, we should search for treatable causes and triggers of neuropsychiatric symptoms like infection, constipation, pain, or polypharmacy. Antipsychotics can be used only if nonpharmacological approaches failed, the patient endangers himself or his surroundings, or the symptoms cause distress to the patient or the caregiver. Before the use of antipsychotics, we should consider whether we could use less effective but safer pharmacological approaches (AChEI or antidepressants). Before the initiation of the treatment with antipsychotics, we should assess the individual risks (particularly the cardiovascular risks) and modify the choice of the medication accordingly. The administration of antipsychotics should always be initiated at a low dose to be titrated up to the minimum effective dose. We should continuously monitor the adverse effects and choose the lowest effective doses possible. The recommended range of doses of antipsychotics is listed in Table 1. The treatment with antipsychotics should be time limited. Initially, it is appropriate to reassess the patient's status at least monthly (or more often, if there was high risk of adverse effects). Later, it should be assessed every 3 months. We should regularly monitor the physical parameters, laboratory variables, and ECG. The initial recommended interval is every 3 months, later every 6 months. If the
Table I Recommended daily doses of antipsychotics to treat BPSD and the available drug forms

\begin{tabular}{ll}
\hline Antipsychotic & Daily dosing \\
\hline Risperidone (tbl., sol.) & $0.25-1 \mathrm{mg}$ \\
Olanzapine (tbl., inj.) & $2.5-7.5 \mathrm{mg}$ \\
Quetiapine (tbl.) & $12.5-150 \mathrm{mg}$ \\
Aripiprazole (tbl., inj.) & $5-10 \mathrm{mg}$ \\
Haloperidol (tbl., gtt., inj.) & $0.5-5 \mathrm{mg}$ \\
\hline
\end{tabular}

Abbreviation: BPSD, behavioral and psychological symptoms of dementia.

condition of the patient did not improve after 2-4 weeks, an increase in the dose or change of the antipsychotic medication would be appropriate. However, first, we should always carefully evaluate the benefits and risks of such an intervention. Conversely, if the condition of the patient improved with the antipsychotic treatment, an attempt to withdraw the antipsychotics should follow within 6-12 weeks. ${ }^{1,6,46}$ The long-term administration of antipsychotics is recommended only in patients with extremely severe initial manifestations of BPSD. In practice, it is not easy to estimate the corresponding duration of the treatment with antipsychotics in patients with dementia. We do not have sufficient data to clearly set the conditions of termination of the treatment. The analysis by the Cochrane Database System Review involved nine randomized studies. ${ }^{66}$ For most patients, discontinuation of the antipsychotic treatment would make no difference. However, two studies showed that the discontinuation of the antipsychotic medication could lead to a relapse, even though it had a positive short-term effect on agitation and psychosis. Two other studies confirmed the risk of this approach in patients with a high degree of initial symptoms (NPI $\geq 14$ points). Occurrence of auditory hallucinations is particularly hazardous. Their presence was related to the significant risk of relapse following the discontinuation of risperidone after 4 weeks of treatment in comparison with the group of patients who continued the antipsychotic medication. ${ }^{67}$ The American Psychiatric Association has recently published guidelines for the use of antipsychotics to treat BPSD. ${ }^{11}$ Recommendations are summarized in Table 2.

\section{Potential drug interactions during the treatment of BPSD}

Elderly patients are at risk of the adverse effects of the medication because of concurrent diseases, polypharmacy, physiological changes in pharmacokinetics and pharmacodynamics of several drugs, and sometimes, because of noncompliance caused by a cognitive deficit or depression. During the BPSD treatment, interactions between administered antipsychotics and long-term prescribed cognition enhancers may occur. 
Table 2 Recommendations on the use of antipsychotics to treat BPSD

\begin{tabular}{|c|c|}
\hline Steps & Recommended procedures \\
\hline Assessment of BPSD & $\begin{array}{l}\text { I. Patients with dementia should be assessed for the type, frequency, severity, clinical pattern, and timing } \\
\text { of the symptoms (IC) } \\
\text { 2. Assess for pain and other potentially modifiable factors and for subtypes of dementia that may } \\
\text { influence the choice of treatment (IC) } \\
\text { 3. Use quantitative measures to assess agitation and psychosis, if present (IC) }\end{array}$ \\
\hline $\begin{array}{l}\text { Development of comprehensive } \\
\text { treatment plan }\end{array}$ & $\begin{array}{l}\text { 4. Individualized treatment plan includes appropriate nonpharmacological and pharmacological } \\
\text { interventions (IC) }\end{array}$ \\
\hline $\begin{array}{l}\text { Assessment of benefits and risks of } \\
\text { antipsychotic treatment for the patient }\end{array}$ & $\begin{array}{l}\text { 5. Antipsychotic medication should be used for treatment of agitation or psychosis only when symptoms } \\
\text { are severe or dangerous and/or cause significant distress to the patient (IB) } \\
\text { 6. Review response to nonpharmacological interventions prior to use of an antipsychotic medication (IC) } \\
\text { 7. If feasible, discuss risk/benefit with the patient and obtain his/her or the caregiver's consent (IC) }\end{array}$ \\
\hline $\begin{array}{l}\text { AP treatment - dosage, duration, } \\
\text { and monitoring }\end{array}$ & $\begin{array}{l}\text { 8. Initiate at a low dose to be titrated up to the minimum effective dose as tolerated (IB) } \\
\text { 9. If significant adverse effects occur, review the patient's status and taper or discontinue the } \\
\text { antipsychotic medication (IC) } \\
\text { I0. If no significant response occurs after } 4 \text { weeks of an adequate dose, taper and withdraw the } \\
\text { medication (IB) } \\
\text { II. If positive response occurs, consider and discuss tapering the dose with the patient/surrogate } \\
\text { regarding experience with tapering attempts (IC) } \\
\text { I2. If adequate response occurs, the dose of antipsychotic medication could be tapered or withdrawn, } \\
\text { unless the patient experienced recurrence of symptoms with prior attempts at tapering (IC) } \\
\text { I3. If the dose of antipsychotic medication is being tapered, assess the symptoms at least monthly for a } \\
\text { minimum of } 4 \text { months after discontinuation to identify recurrence of symptoms (IC) }\end{array}$ \\
\hline $\begin{array}{l}\text { Use of specific antipsychotic medication, } \\
\text { depending on clinical context }\end{array}$ & $\begin{array}{l}\text { 14. In the absence of delirium, haloperidol should not be used as a first-line agent (IB) } \\
\text { 15. Long-acting injectable antipsychotics should not be used, unless it is indicated for co-occurring } \\
\text { psychotic disorder (IB) }\end{array}$ \\
\hline
\end{tabular}

Notes: Recommendations in brackets: I=recommended - benefits of the intervention overweigh its harms, $2=$ uncertain benefit/potential harm ratio. Strength of evidence: A - high, B - moderate, C - low."

Abbreviation: BPSD, behavioral and psychological symptoms of dementia.

AChEI have relatively few pharmacokinetic interactions. Metabolism of donepezil and galantamine could be influenced by substrates, inductors, or inhibitors of cytochrome oxidase system CYP2D6 and CYP3A4. Given the metabolization by two isoenzymes, the competitive inhibition by others of their substrates does not have to be clinically relevant (eg, during concurrent administration of donepezil and sertraline). Paroxetine, a strong CYP2D6 inhibitor, can increase the levels of galantamine by $30 \%-40 \%{ }^{68}$ Interactions tend to get worse during hepatic and renal impairment. Rivastigmine and memantine have extrahepatic metabolism (Table 3).

The concurrent administration of AChEI with anticholinergic-acting medication is among the clinically significant pharmacodynamic interactions. This involves several antipsychotic and antidepressant medications for the treatment of BPSD. Antihistamines and some bronchodilators also have anticholinergic effects. These drugs deteriorate cognition and have an antagonistic effect on AChEI. Still, one-third of patients treated with AChEI are concurrently prescribed the anticholinergic-acting medication. ${ }^{69}$ AChEI modify cardiac and cerebral functions by stimulating the parasympathetic system. Inhibition of cholinesterase reduces acetylcholine degradation and contributes to slowing the heart rate. AChEI also increase blood pressure through central M1 and M2 cholinergic receptors. Hence, the interaction with antipsychotics or antidepressants that slow the heart rate and prolong the QTc interval on ECG leads to bradycardia and can increase the risk of syncope and mortality. Metabolism and conceivable interaction of cognitive enhancers are summarized in Table 3.

\section{Conclusion}

The behavioral and psychological symptoms represent a common complication in patients with dementia. Predominantly, they comprise psychosis, agitation and mood disorders, disinhibited behavior, impairment of the sleep and wakefulness rhythm, wandering, perseveration, pathological collecting, shouting, etc. Their occurrence is related to more rapid progression of the disease, earlier institutionalization, use of physical constraints, and higher risk of mortality. It leads to higher costs of care provided and greater distress for caregivers. The authors of this study believe that nonpharmacological approaches should be the first choice in the treatment of behavioral and psychological symptoms. 
Table 3 Summary of metabolism, pharmacokinetic, and pharmacodynamic interactions of cognitive enhancers ${ }^{\mathrm{a}}$

\begin{tabular}{|c|c|c|c|c|}
\hline Drugs & Metabolism & $\begin{array}{l}\text { Drugs increasing } \\
\text { levels }\end{array}$ & $\begin{array}{l}\text { Drugs decreasing } \\
\text { levels }\end{array}$ & Pharmacodynamic interactions \\
\hline Donepezil & CYP3A4 and 2D6 & $\begin{array}{l}\text { Fluoxetine } \\
\text { Ketoconazole } \\
\text { Itraconazole } \\
\text { Erythromycin } \\
\text { Quinidine }\end{array}$ & $\begin{array}{l}\text { Rifampicin } \\
\text { Phenytoin } \\
\text { Carbamazepine } \\
\text { Alcohol }\end{array}$ & $\begin{array}{l}\text { Anticholinergic medication - An } \\
\text { Cholinomimetics (succinylcholine) - S } \\
\text { Peripheral ChE-I (neostigmine) - S } \\
\text { Beta blockers - CV } \\
\text { Amiodarone - CV } \\
\text { Ca channel blockers - CV }\end{array}$ \\
\hline Rivastigmine & Extrahepatic & - & - & $\begin{array}{l}\text { Anticholinergic medication - An } \\
\text { Cholinomimetics (succinylcholine) - S } \\
\text { Peripheral ChE-I (neostigmine) - S } \\
\text { Beta blockers - CV } \\
\text { Amiodarone - CV } \\
\text { Ca channel blockers - CV }\end{array}$ \\
\hline Galantamine & CYP3A4 and 2D6 & $\begin{array}{l}\text { Paroxetine } \\
\text { Fluoxetine } \\
\text { Fluvoxamine } \\
\text { Amitriptyline } \\
\text { Ketoconazole } \\
\text { Erythromycin } \\
\text { Ritonavir } \\
\text { Quinidine }\end{array}$ & $?$ & $\begin{array}{l}\text { Anticholinergic medication - An } \\
\text { Cholinomimetics (succinylcholine) - S } \\
\text { Peripheral ChE-I (neostigmine) - S } \\
\text { Beta blockers - CV } \\
\text { Amiodarone - CV } \\
\text { Ca channel blockers - CV }\end{array}$ \\
\hline Memantine & $\begin{array}{l}\text { Primarily } \\
\text { extrahepatic, } \\
\text { renal excretion }\end{array}$ & $\begin{array}{l}\text { Cimetidine } \\
\text { Ranitidine } \\
\text { Procainamide } \\
\text { Quinidine } \\
\text { Nicotine } \\
\text { Urine alkalizing drugs }\end{array}$ & $?$ & $\begin{array}{l}\text { Increase in effect of L-dopa, dopaminergic and } \\
\text { anticholinergic medication } \\
\text { Amantadine, ketamine, dextromethorphan - FTP } \\
\text { It is necessary to adjust the dosage of spasmolytic } \\
\text { medication, dantrolene, and baclofen }\end{array}$ \\
\hline
\end{tabular}

Notes: according to Taylor et al' and Masopust et al. ${ }^{62}$ 'Carbonic anhydrase inhibitors (diuretics), sodium bicarbonate. The question mark (?) indicates "unknown". The en dash (-) indicates "none".

Abbreviations: An, antagonistic effect; CV, effect on cardiac action, slowing of transduction; FTP, risk of pharmacotoxic psychosis; S, synergic effect.

The pharmacological therapy should be initiated only if the symptoms were not caused by somatic causes, did not respond to nonpharmacological interventions, or were not caused by prior medication. AChEI, memantine, antipsychotics, antidepressants, mood stabilizers, and benzodiazepines are used. In practice, antipsychotics are prescribed most often, although we do not possess solid evidence about their efficacy on individual neuropsychiatric symptoms, and concurrently, their administration is related to high risk of occurrence of adverse effects and increased mortality. Therefore, antipsychotics should be used only when safer interventions fail or when the patient endangers him/herself or his/her surroundings with his/her symptoms or when the symptoms cause excessive distress to the patient or the caregivers. Prior to initiation of the antipsychotic medication, somatic examination including ECG should be performed, individual risk should be assessed, and the choice of specific medication should be assessed differentially. Generally, compared with the common population, lower doses should be used and titrated gradually. During the treatment, physical parameters and occurrence of adverse effects should be monitored regularly. The withdrawal of antipsychotic medication should be attempted in time in patients with lower initial intensity of symptoms. When choosing the medication, pharmacokinetic and pharmacodynamic interaction with AChEI and memantine used by majority of patients with dementia should be considered.

\section{Acknowledgments}

This paper was supported by the research project PROGRES Q40 run at the Medical Faculty of Charles University and by MH CZ - DRO (UHHK 00179906) and by the project Excellence 2018, run at the Faculty of Informatics and Management of the University of Hradec Kralove, Czech Republic.

\section{Author contributions}

All authors contributed equally toward data analysis, drafting and critically revising the paper and agree to be accountable for all aspects of the work.

\section{Disclosure}

The authors report no conflicts of interest in this work. 


\section{References}

1. Taylor D, Paton C, Kapur S. Prescribing Guidelines in Psychiatry. 12th ed. West Sussex, UK: John Wiley \& Sons; 2015.

2. Azermai M. Dealing with behavioral and psychological symptoms of dementia: a general overview. Psychol Res Behav Manag. 2015;8: $181-185$.

3. Nagata T, Shinagawa S, Nakajima S, et al. Classification of neuropsychiatric symptoms requiring antipsychotic treatment in patients with Alzheimer's disease: analysis of the CATIE-AD Study. J Alzheimers Dis. 2016;50:839-845.

4. Tible OP, Riese F, Savaskan E, von Gunten A. Best practice in the management of behavioural and psychological symptoms of dementia. Ther Adv Neurol Disord. 2017;10:297-309.

5. Preuss UW, Wong JWM, Koller G. [Treatment of behavioral and psychological symptoms of dementia: a systematic review]. Psychiatr Pol. 2016;50:679-715. Polish.

6. Azermai M, Petrovic M, Elseviers MM, et al. Systematic appraisal of dementia guidelines for the management of behavioural and psychological symptoms. Ageing Res Rev. 2012;11:78-86.

7. Selbaek G, Kirkevold $\varnothing$, Engedal K. The course of psychiatric and behavioral symptoms and the use of psychotropic medication in patients with dementia in Norwegian nursing homes - a 12-month follow-up study. Am J Geriatr Psychiatry. 2008;16:528-536.

8. Ballard C, Corbett A. Management of neuropsychiatric symptoms in people with dementia. CNS Drugs. 2010;24(9):729-739.

9. Trifiró G, Sultana J, Spina E. Are the safety profiles of antipsychotic drugs used in dementia the same? An updated review of observational studies. Drug Saf. 2014;37:501-520.

10. Protopopová D, Masopust J, Vališ M, et al. Použití antipsychotik u nemocných s demencí. Cesk Slov Neurol. 2015;78(111):158-162.

11. Reus VI, Fochtmann LJ, Eyler AE, et al. The American Psychiatric Association Practice Guideline on the use of antipsychotics to treat agitation or psychosis in patients with dementia. Am J Psychiatry. 2016; 173:543-546.

12. van der Spek K, Gerritsen DL, Smalbrugge M, et al. Only $10 \%$ of the psychotropic drug use for neuropsychiatric symptoms in patients with dementia is fully appropriate. The PROPER I-study. Int Psychogeriatr. 2016;28:1589-1595.

13. Casanova MF, Starkstein SE, Jellinger KA. Clinicopathological correlates of behavioral and psychological symptoms of dementia. Acta Neuropathol. 2011;122(2):117-135.

14. Abraha I, Rimland JM, Trotta FM, et al. Systematic review of systematic reviews of non-pharmacological interventions to treat behavioural disturbances in older patients with dementia. The SENATOR-OnTop series. BMJ Open. 2017;7(3):e012759.

15. Kuronen M, Kautiainen H, Karppi P, Hartikainen S, Koponen H. Antipsychotic drug use and associations with neuropsychiatric symptoms in persons with impaired cognition: a cross-sectional study. Nord $J$ Psychiatry. 2016;70:621-625.

16. Rozzini L, Chilovi BV, Conti M, et al. Efficacy of SSRIs on cognition of Alzheimer's disease patients treated with cholinesterase inhibitors. Int Psychogeriatr. 2010;22:114-119.

17. Nowrangi MA, Lyketsos CG, Rosemberg PB. Principles and management of neuropsychiatric symptoms in Alzheimer's dementia. Alzheimers Res Ther. 2015;7(1):12.

18. Seitz DP, Andunuri N, Gill SS, Gruneir A, Herrmann N, Rochon P. Antidepressants for agitation and psychosis in dementia. Cochrane Database Syst Rev. 2011;16(2):CD008191.

19. Seitz DP, Gill SS, Herrmann N, et al. Pharmacological treatments for neuropsychiatric symptoms of dementia in long-term care: a systematic review. Int Psychogeriatr. 2013;25:185-203.

20. Schneider LS, Frangakis C, Drye LT, et al; CitAD Research Group. Heterogeneity of treatment response to citalopram for patients with Alzheimer's disease with aggression or agitation: the CitAD randomized clinical trial. Am J Psychiatry. 2016;173:465-472.
21. Leonpacher AK, Peters ME, Drye LT, et al; CitAD Research Group. Effects of citalopram on neuropsychiatric symptoms in Alzheimer's dementia: evidence from the CitAD study. Am J Psychiatry. 2016;173: 473-480.

22. Viscogliosi G, Chiriac IM, Ettorre E. Efficacy and safety of citalopram compared to atypical antipsychotics on agitation in nursing home residents with Alzheimer dementia. J Am Med Dir Assoc. 2017;18: 799-802.

23. Lebert F, Stekke W, Hasenbroekx C, Pasquier F. Frontotemporal dementia: a randomised, controlled trial with trazodone. Dement Geriatr Cogn Disord. 2004;17:355-359.

24. Cakir S, Kulaksizoglu IB. The efficacy of mirtazapine in agitated patients with Alzheimer's disease: a 12-week open-label pilot study. Neuropsychiatr Dis Treat. 2008;4:963-966.

25. Yeh YC, Ouyang WC. Mood stabilizers for the treatment of behavioral and psychological symptoms of dementia: an update review. Kaohsiung J Med Sci. 2012;28:185-193.

26. Sival RC, Haffmans PM, Jansen PA, Duursma SA, Eikelenboom P. Sodium valproate in the treatment of aggressive behavior in patients with dementia - a randomized placebo controlled clinical trial. Int $J$ Geriatr Psychiatry. 2002;17:579-585.

27. Konovalov S, Muralee S, Tampi RR. Anticonvulsants for the treatment of behavioral and psychological symptoms of dementia: a literature review. Int Psychogeriatr. 2008;20:293-308.

28. Campbell N, Ayub A, Boustani MA, et al. Impact of cholinesterase inhibitors on behavioral and psychological symptoms of Alzheimer's disease: a meta-analysis. Clin Interv Aging. 2008;3:719-728.

29. Kishi T, Matsunaga S, Iwata N. The effects of memantine on behavioral disturbances in patients with Alzheimer's disease: a meta-analysis. Neuropsychiatr Dis Treat. 2017;13:1909-1928.

30. Tan CC, Yu JT, Wang HF, et al. Efficacy and safety of donepezil, galantamine, rivastigmine, and memantine for the treatment of Alzheimer's disease: a systematic review and meta-analysis. J Alzheimers Dis. 2014; 41(2):615-631.

31. Wang J, Yu JT, Meng XF, et al. Pharmacological treatment of neuropsychiatric symptoms in Alzheimer's disease: a systematic review and meta-analysis. J Neurol Neurosurg Psychiatry. 2015;86(1):101-109.

32. Chen R, Chan PT, Chu H, et al. Treatment effects between monotherapy of donepezil versus combination with memantine for Alzheimer disease: a meta-analysis. PLoS One. 2017;12(8):e0183586.

33. Savaskan E, Mueller H, Hoerr R, et al. Treatment effects of Ginkgo biloba extract EGb $761^{\circledR}$ on the spectrum of behavioral and psychological symptoms of dementia: meta-analysis of randomized controlled trials. Int Psychogeriatr. 2017;21:1-9.

34. Saarelainen L, Taipale H, Koponen M, von Gunten A, Gauthier S. The incidence of benzodiazepine and related drug use in persons with and without Alzheimer's disease. J Alzheimers Dis. 2016;49:809-818.

35. Tampi RR, Tampi DJ. Efficacy and tolerability of benzodiazepines for the treatment of behavioral and psychological symptoms of dementia: a systematic review of randomized controlled trials. Am J Alzheimers Dis Other Demen. 2014;29:565-574.

36. Gentile S. Second-generation antipsychotics in dementia: beyond safety concerns. A clinical, systematic review of efficacy data from randomized controlled trials. Psychopharmacology. 2010;212:119-129.

37. US FDA. Public Health Advisory: deaths with antipsychotics in elderly patients with behavioral disturbances; 2005. Available from: http://www.fda.gov/drugs/drugsafety/postmarketdrugsafetyinformationforpatientsandproviders/drugsafetyinformationforheathcareprofessionals/publichealthadvisories/ucm053171.htm. Accessed January 20, 2018.

38. Kales HC, Kim HM, Zivin K, et al. Risk of mortality among individual antipsychotics in patients with dementia. Am J Psychiatry. 2012;169: 71-79.

39. Suh GH, Greenspan AJ, Choi SK. Comparative efficacy of risperidone versus haloperidol on behavioural and psychological symptoms of dementia. Int J Geriatr Psychiatry. 2006;21:654-660. 
40. Maher AR, Theodore G. Summary of the comparative effectiveness review on off-label use of atypical antipsychotics. J Manag Care Pharm. 2012;18(5 supp1 B):S1-S20.

41. Schneider LS, Tariot PN, Dagerman KS, et al; CATIE-AD Study Group. Effectiveness of atypical antipsychotic drugs in patients with Alzheimer's disease. N Engl J Med. 2006;355:1525-1538.

42. Tan L, Wang HF, Wang J, et al. Efficacy and safety of atypical antipsychotic drug treatment for dementia: a systematic review and metaanalysis. Alzheimers Res Ther. 2015;7(1):20.

43. Barnes TR, Banerjee S, Collins N, Treloar A, McIntyre SM, Paton C. Antipsychotics in dementia: prevalence and quality of antipsychotic drug prescribing in UK mental health services. Br J Psychiatry. 2012; 201:221-226.

44. Yoshida K, Roberts R, Suzuki T, et al. Lack of early improvement with antipsychotics is a marker for subsequent nonresponse in behavioral and psychological symptoms of dementia: analysis of CATIE-AD data. Am J Geriatr Psychiatry. 2017;25:708-716.

45. Reeves S, Bertrand J, McLachlan E, et al. A population approach to guide amisulpride dose adjustments in older patients with Alzheimer's disease. J Clin Psychiatry. 2017;78:e844-e851.

46. Steinberg M, Lysketos CG. Atypical antipsychotic use in patients with dementia: managing safety concerns. Am J Psychiatry. 2012;169: 900-906.

47. Stahl SM. The Prescriber's Guide. 4th ed. Cambridge: Cambridge Universtiy Press; 2013.

48. Ballard C, Lana MM, Theodoulou M, et al; On behalf of the investigators DART AD. A randomised, blinded, placebo-controlled trial in dementia patients continuing or stopping neuroleptics (the DART AD trial). PLoS Medicine. 2008;5(4):587-599.

49. Ballard C, Howard R. Neuroleptic drugs in dementia: benefits and harm. Nat Rev Neurosci. 2006;7(6):492-500.

50. Wolf A, Leucht S, Pajonk FG. Do antipsychotics lead to cognitive impairment in dementia? A meta-analysis of randomised placebo-controlled trials. Eur Arch Psychiatry Clin Neurosci. 2017;267:187-198.

51. Wang PS, Schneeweiss S, Avorn J, et al. Risk of death in elderly users of conventional vs. atypical antipsychotic medications. N Engl J Med. 2005;353(22):2335-2341.

52. Schneeweiss S, Setoguchi S, Brookhart A, Dormuth C, Wang PS. Risk of death associated with the use of conventional versus atypical antipsychotic drugs among elderly patients. CMAJ. 2007;176:627-632.

53. Kales HC, Valenstein M, Kim HM, et al. Mortality risk in patients with dementia treated with antipsychotics versus other psychiatric medications. Am J Psychiatry. 2007;164:1568-1576.

54. US FDA. Information on conventional antipsychotics; 2008. Available from: http://www.fda.gov/drugs/drugsafety/postmarketdrugsafetyinformationforpatientsandproviders/ucm107211.htm. Accessed January 20, 2018.
55. Huybrechts KF, Gerhard T, Crystal S, et al. Differential risk of death in older residents in nursing homes prescribed specific antipsychotic drugs: population based cohort study. BMJ. 2012;344:e977.

56. Ballard C, Hanney ML, Theodoulou M, et al. The dementia antipsychotic withdrawal trial (D A R T - A D); long-term follow-up of a randomised placebo-controlled trial. Lancet Neurol. 2009;8:151-157.

57. Sacchetti E, Turrina C, Valsecchi P. Cerebrovascular accidents in elderly people treated with antipsychotic drugs. Drug Saf. 2010;33: 273-288.

58. Hsu WT, Esmaily-Fard A, Lai CC, et al. Antipsychotics and the risk of cerebrovascular accident: a systematic review and meta-analysis of observational studies. J Am Med Dir Assoc. 2017;18:692-699.

59. Trifiró G. Antipsychotic drug use and community-acquired pneumonia. Curr Infect Dis Rep. 2011;13:262-268.

60. Nielsen J, Graff C, Kanters JK, Toft E, Taylor D, Meyer JM. Assessing QT interval prolongation and its associated risks with antipsychotics. CNS Drugs. 2011;25:473-490.

61. American Geriatrics Society 2012 Beers Criteria Update Expert Panel. American Geriatrics Society updated Beers Criteria for potentially inappropriate medication use in older adults. J Am Geriatr Soc. 2012; 60:616-631.

62. Masopust J, Malý R, Vališ M. Risk of venous thromboembolism during treatment with antipsychotic agents. Psychiatry Clin Neurosci. 2012;66: $541-552$.

63. Schmedt N, Garbe E. Antipsychotic drug use and the risk of venous thromboembolism in elderly patients with dementia. $J$ Clin Psychopharmacol. 2013;33:753-778.

64. Zheng L, Mack WJ, Dagerman KS, et al. Metabolic changes associated with second generation antipsychotic use in Alzheimer's disease patients: the CATIE-AD study. Am J Psychiatry. 2009;166:583-590.

65. Rondanelli M, Sarra S, Antoniello N, et al. No effect of atypical antipsychotic drugs on weight gain and risk of developing type II diabetes or lipid abnormalities among nursing home elderly patients with Alzheimer's disease. Minerva Med. 2006;97:147-151.

66. Declercq T, Petrovic M, Azermai M, et al. Withdrawal versus continuation of chronic antipsychotic drugs for behavioural and psychological symptoms in older people with dementia. Cochrane Database Syst Rev. 2013;3:CD007726.

67. Patel AN, Lee S, Andrews HF, et al. Prediction of relapse after discontinuation of antipsychotic treatment in Alzheimer's disease: the role of hallucinations. Am J Psychiatry. 2017;174:362-369.

68. Pasqualetti G, Tognini S, Calsolaro V, Polini A, Monzani F. Potential drug-drug interactions in Alzheimer patients with behavioral symptoms. Clin Interv Aging. 2015;10:1457-1466.

69. Carnahan RM, Lund BC, Perry PJ, Chrischilles EA. The concurrent use of anticholinergics and cholinesterase inhibitors: rare event or common practice? J Am Geriatr Soc. 2004;52:2082-2087.
Neuropsychiatric Disease and Treatment

\section{Publish your work in this journal}

Neuropsychiatric Disease and Treatment is an international, peerreviewed journal of clinical therapeutics and pharmacology focusing on concise rapid reporting of clinical or pre-clinical studies on a range of neuropsychiatric and neurological disorders. This journal is indexed on PubMed Central, the 'PsycINFO' database and CAS,

\section{Dovepress}

and is the official journal of The International Neuropsychiatric Association (INA). The manuscript management system is completely online and includes a very quick and fair peer-review system, which is all easy to use. Visit http://www.dovepress.com/testimonials.php to read real quotes from published authors. 